\title{
Full thoracoscopic segmentectomies for lung cancer: rational of a multiportal fissure-based approach
}

\author{
Dominique Gossot $^{1} \wedge$, Alessio Vincenzo Mariolo ${ }^{1}$, Emmanuel Brian $^{1}$, Guillaume Boddaert ${ }^{1}$, \\ Agathe Seguin-Givelet ${ }^{1,2}$
}

${ }^{1}$ Thoracic Department, Curie-Montsouris Thorax Institute-Institut Mutualiste Montsouris, Paris, France; ${ }^{2}$ Paris 13 University, Sorbonne Paris Cité, Faculty of Medicine SMBH, Bobigny, France

Contributions: (I) Conception and design: D Gossot; (II) Administrative support: D Gossot, A Seguin-Givelet; (III) Provision of study materials or patients: None; (IV) Collection and assembly of data: None; (V) Data analysis and interpretation: None; (VI) Manuscript writing: All authors; (VII) Final approval of manuscript: All authors.

Correspondence to: Dominique Gossot. Thoracic Department, Curie-Montsouris Thorax Institute - Institut Mutualiste Montsouris, 42 Bd Jourdan, F-75014 Paris, France. Email: dominique.gossot@imm.fr.

\begin{abstract}
Following the partial results of ongoing randomized trials, thoracoscopic anatomic sublobar resections (SLRs) may become the standard treatment of ground-glass opacities (GGO) and of some early- stage lung carcinomas. However, these procedures are challenging. The performance of closedchest pulmonary segmentectomies, especially for complex ones, requires a meticulous dissection of bronchovascular elements. A thorough preparation facilitates the procedure. In this article, we review the different technical and technological aspects of the multiportal approach with fissure-first dissection. Prerequisites are (I) precise preoperative study of the anatomical variations, based on 3D reconstructions or 3D printing, (II) preoperative evaluation of safety margins, based on a virtual margin, (III) for small nodules, localization of the target using either preoperative or intraoperative marking, (IV) fissure-based approach to allow extensive dissection of bronchovascular elements, $(\mathrm{V})$ intraoperative analysis of resection margins and intersegmental lymph nodes in order to extend resection in case on invaded margin or lymph node, (VI) accurate delineation and division of the intersegmental plane. Technical and technological helpful means are discussed in this article.
\end{abstract}

Keywords: Segmentectomy; thoracoscopy; 3D modelization; infrared imaging

Received: 25 May 2021; Accepted: 14 July 2021; Published: 20 July 2022.

doi: 10.21037 /jovs-21-30

View this article at: https://dx.doi.org/10.21037/jovs-21-30

Although thoracoscopic lobectomies have been regarded for years as difficult procedures, they have finally been adopted and have almost become routine surgery in many centers.

Closed-chest sublobar resections (SLRs) are attracting a great deal of interest as evidenced by the increasing number of publications (1). However, unlike lobectomies, they prove to be a much more difficult technical challenge for thoracic surgeons. They do not just involve surgical skills but also new technologies. Some publications report a learning curve ranging between 30 and 80 cases (2-5). These publications are questionable because an analysis of the data shows that they include very few complex segmentectomies. After an experience of 750 thoracoscopic segmentectomies, we consider the cutoff for the learning curve, if any, to be at a much higher level. For our team, some complex segmentectomies still pose problems and, as Sato et al. we do regard some basilar resections as one of the most challenging procedures (6). There are several

^ ORCID: 0000-0002-7038-1924. 

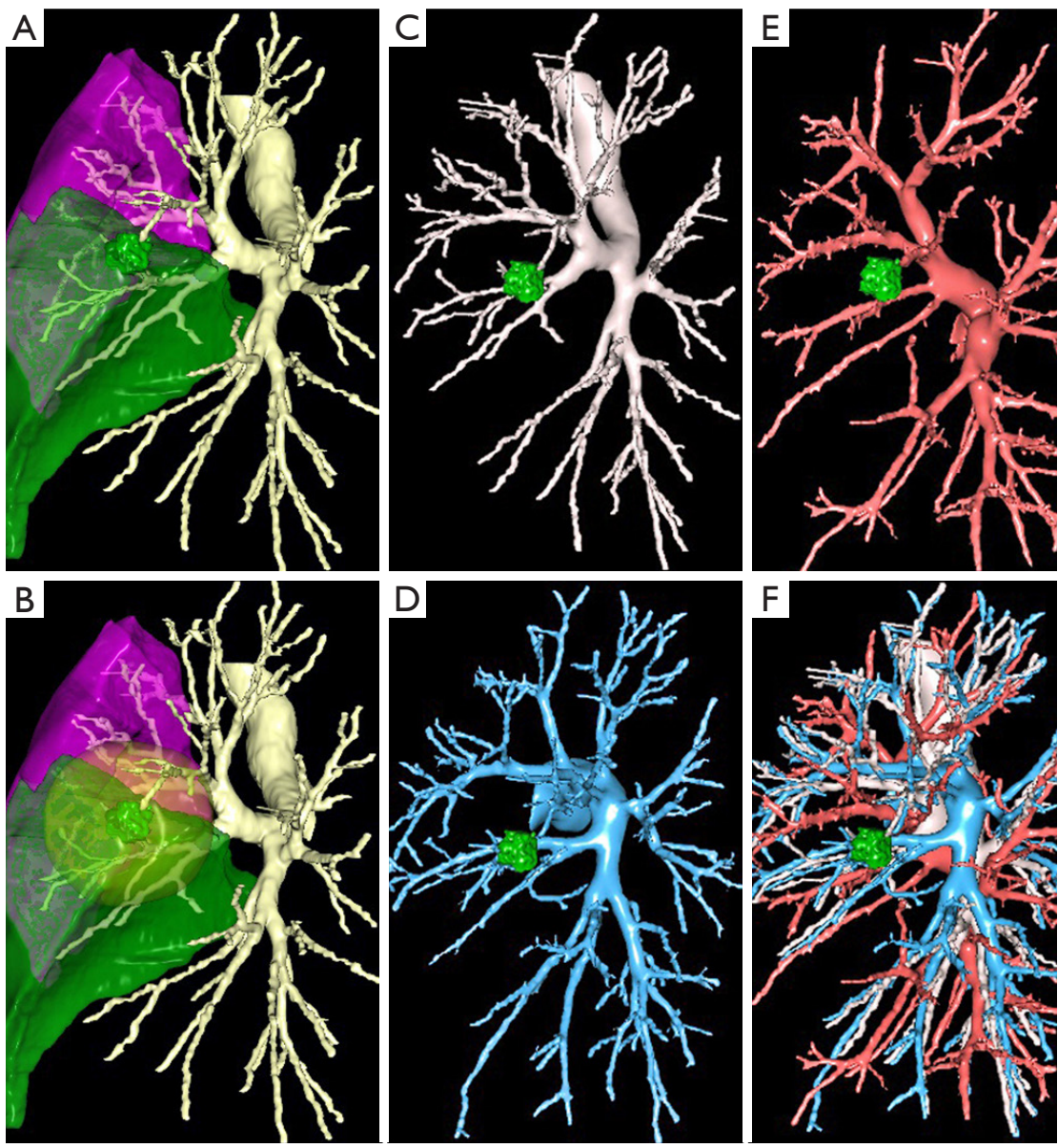

Figure 1 Example of 3D modelization used for planification of a thoracoscopic segmentectomy for a lingular NSCLC. (A) Standard view (lingula in green, $S^{3}$ in purple), (B) standard view with virtual security margin (pale yellow sphere) indicating resection should be extended to $\mathrm{S}^{3},(\mathrm{C})$ bronchi alone, (D) arteries alone, (E) veins alone, (F) global view with bronchi, arteries and veins. NSCLC, non-small cell lung cancer.

reasons for this: (I) anatomical variations are frequent $(7,8)$ and require an extensive dissection within the fissure; (II) some segmentectomies are difficult to perform without preoperative mapping (9) and (III) management of the intersegmental plane can be tricky, especially for basilar segmentectomies (6).

The purpose of this article is to give some keys that we find useful, whatever the approach used. We will not detail the basic notions of patient positioning, trocars and the equipment used, that can be found elsewhere $(10,11)$. We will only deal here with the principles that are applied in our department and that could apply to any other technique whatever the approach. Even more than for other procedures, preparation is of key importance.

\section{Preoperative study of the anatomy}

One of the difficulties of thoracoscopic anatomical segmentectomies (TAS) is the understanding of the anatomy of the bronchovascular pedicles. Some segments have an almost constant and an easily comprehensible anatomy, for example $S^{6}$ or $S^{4+5}$ resections (lingulectomy). In other cases, there may be variations that are important to know, for example the presence of a mediastinal lingular artery during a left upper trisegmentectomy. A precise study of the preoperative CT can give indications. But only 3-dimensional (3D) reconstructions allow an accurate study of vessels and bronchi (9,12-14) (Figure 1). It shows precisely the number, size and direction of segmental bronchi, arteries and veins. For simple resections, the need 


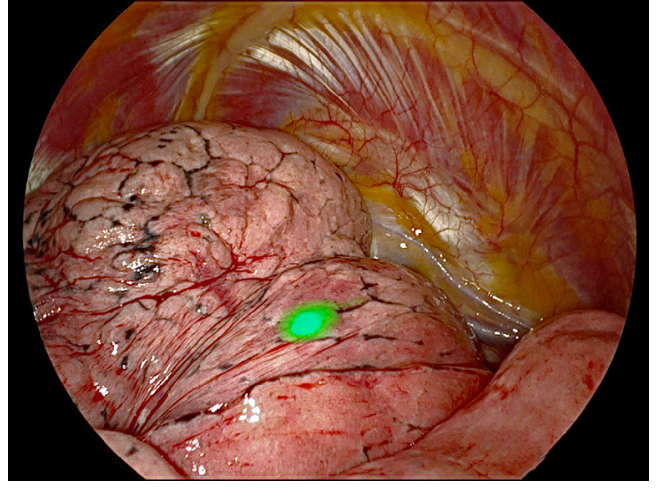

Figure 2 Localization of a target nodule of the right upper lobe by infrared imaging after transbronchial injection of indocyanine green.

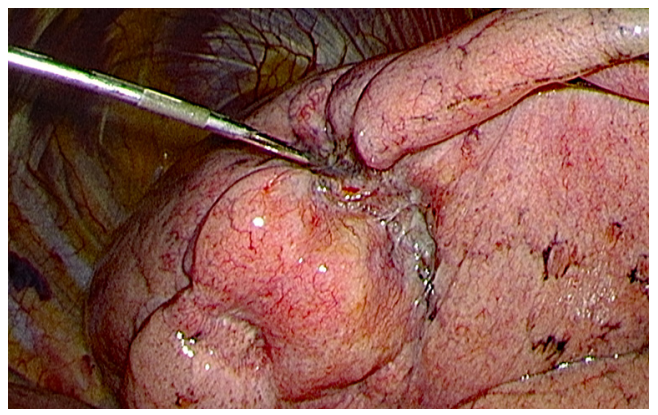

Figure 3 Intraoperative needle-biopsy of a c'T1aN0 target nodule of the right upper lobe.

for preoperative $3 \mathrm{D}$ reconstruction may eventually decrease with growing experience (although it is still desirable), but $3 \mathrm{D}$-modeling or $3 \mathrm{D}$-printing is essential for complex segmentectomies, especially those of the lower lobe $(6,15)$.

\section{Preoperative localization of the target}

TAS are most often performed for early-stage tumors, i.e., small-sized, whose localization does not always give a preoperative pathological diagnosis, even using sophisticated techniques such as radial-EBUS or electromagnetic bronchial navigation (16). It is therefore important to be able to localize the target lesion. Until recently, the most common technique was preoperative CT-guided marking using a hook-wire or methylene blue or a combination of both methods (9). It has several disadvantages: discomfort or chest pain in some patients, pneumothorax, mobilization of the harpoon during patient transport, and even more

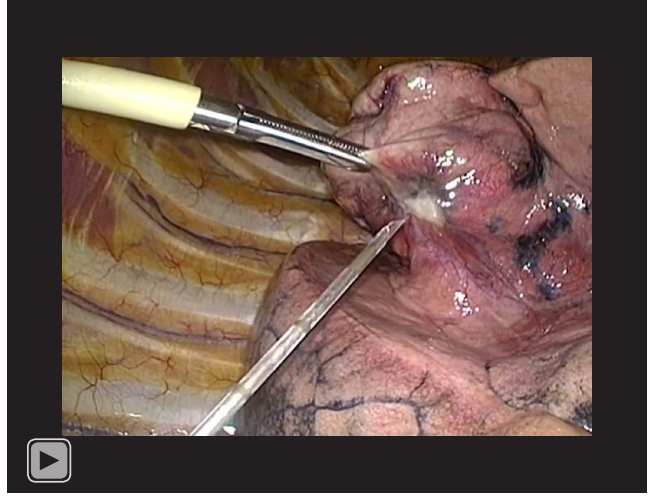

Video 1 Needle biopsy under thoracoscopic control of a small nodule in right segment 2 .

serious accidents such as embolism. Placement of a coil has less morbidity but often interferes with the pathological examination. Preoperative marking by endobronchial approach under ENB after injection of methylene blue or indocyanine green (ICG) under infrared imaging is more precise, has no morbidity and can be done by the surgeon himself in the same operating time. It is now our routine technique. In our first 48 patients, the success rate of ENBguided localization of lung nodules was $94 \%$, this after an acceptable learning curve (17) (Figure 2).

\section{Obtaining a pathological diagnosis}

Anatomical segmentectomies are mostly indicated in stage I bronchial cancers, which means that the tumor is often small and not easily accessible to a percutaneous biopsy under CT. Some patients are therefore operated on without preoperative diagnosis. Wedge resection can distort the specimen and make the pathological study unreliable. When the lesion is localizable, it is therefore preferable to perform a needle biopsy (Figure 3; Video 1). The yield of these biopsies is as high as $90 \%$. In case of failure, a resection using a vessel sealing device, with temporary or permanent closure of the pneumotomy by an absorbable running suture, is preferable to a resection by stapling. In some cases, especially in ground-glass lesions, intraoperative examination may not be possible and segmentectomy will therefore be both diagnostic and therapeutic.

\section{Fissure-based approach}

So-called "fissure-last" techniques are not applicable 


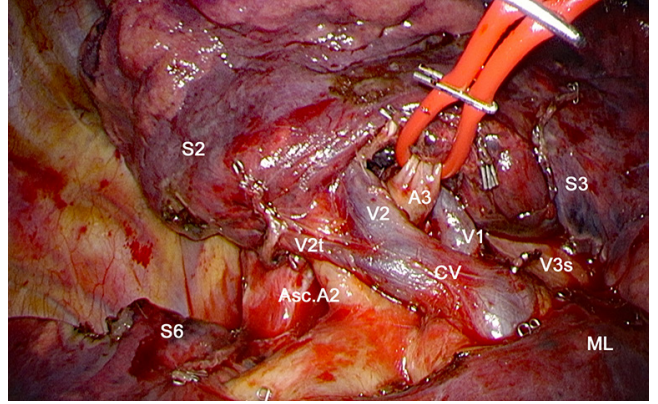

Figure 4 Example of an extensive venous dissection in the fissure, during a right $\mathrm{S}^{3}$ segmentectomy.

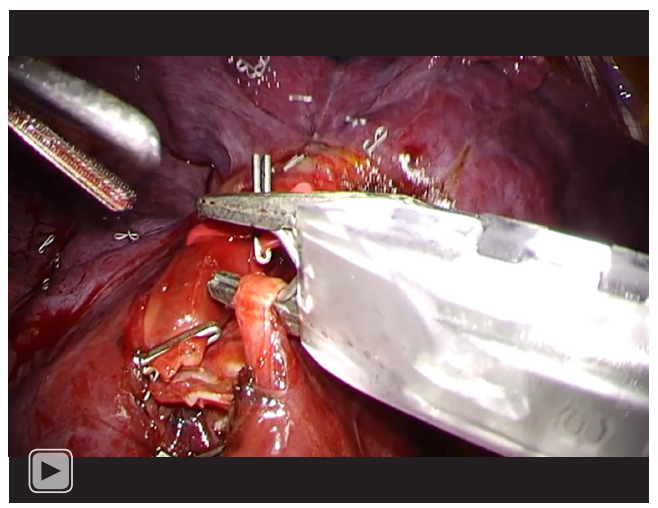

Video 2 Arterial dissection (A8a and A8b) in the fissure during a right $\mathrm{S} 8$ thoracoscopic segmentectomy.

for TAS because vascular dissection within the fissure is essential to detect anatomical variations. Extensive dissection using a "fissure-first" approach provides the best exposure of the segmental pedicle elements (Figure 4) (18) (Video 2).

Access to the segmental branches of the pulmonary artery is more or less easy depending on whether the fissure is open or fused. The opening of a fused fissure can be a tedious part of the procedure and a source of oozing. It is always troublesome in thoracoscopy where the operating field must remain as "dry" as possible to maintain an optimal view. One of the keys to a non-hemorrhagic dissection in the fissure is to progress cautiously and step by step, from the periphery towards the hilum. Thin instruments, such as ultrasound scissors or electrother ${ }^{\mathrm{TM}}$ mal bipolar sealer, are less cumbersome and just as effective as a stapler for sectioning the peripheral and thin part of a fissure. For its central and thicker part, a stapler remains necessary.

In some segmentectomies, it is not useful to open the fissures completely, thus limiting the mobility of the remaining segment(s) and preventing segmental torsion (19-21). If the fissure had to be completely opened, it may be necessary to secure a mobile segment, for example by anchoring $\mathrm{S}^{6}$ to $\mathrm{S}^{2}$ after a basilar segmentectomy or the lingula to $\mathrm{S}^{8}$ after a left upper division segmentectomy. This is achieved thanks to a running suture, usually using $\mathrm{V}-\mathrm{Loc}^{\mathrm{TM}}$.

\section{Delineation of the intersegmental plane}

One of the difficulties of thoracoscopic segmentectomies is the delineation and separation of the intersegmental plane. This step is particularly complex in basilar segmentectomies because of its three-dimensional pyramidal shape $(6,15,22)$. By thoracotomy, this step is facilitated by palpation and by manual traction that can be exerted on the segment along the intersegmental vein. By thoracoscopy, the surgeon cannot use his/her hand and the limited space associated with the lack of distance do not allow perfect exposure of the anatomy. This is why, in almost all recent series, the intersegmental plane is stapled, despite certain disadvantages of stapling, in particular possible plication of the parenchyma (23). Stapling does not obviate the need for precise marking of the segmental boundaries.

Several methods have been described.

Method 1: the most commonly used technique is the creation of a delineation line between ventilated and nonventilated lung, by re-ventilating the operated lung after the segmental bronchus has been stapled (10). Once the plane is found, it may be useful to mark the boundary between ventilated and nonventilated lung by cautery dots or by applying a clamp. This method has two disadvantages: (I) re-expansion of the lung interferes with vision; (II) the segment(s) to be resected may be partially re-ventilated by Kohn's pores and Lambert's ducts, which does not allow a clear demarcation (Video 3).

Method 2: for this reason, some authors have suggested a reverse technique: (I) place the stapler over the bronchus, without closing it; (II) reventilate the entire operated lung; (III) staple the bronchus; (IV) exclude the lung again. Thus, only the segment(s) to be resected remain expanded.

In practice, this method may also have disadvantages: before performing it, one must be sure that the resection is completed because the volume of the aerated segments can be troublesome and hamper dissection.

Method 3: the segmental bronchus is selectively catheterized through a fiberscope and jet ventilation is 


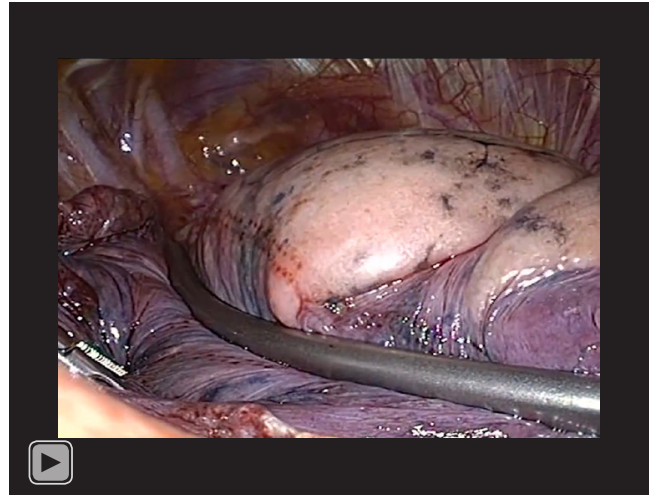

Video 3 Delineation of the intersegmental plane during a right S1+2 segmentectomy by a ventilation-deflation method.

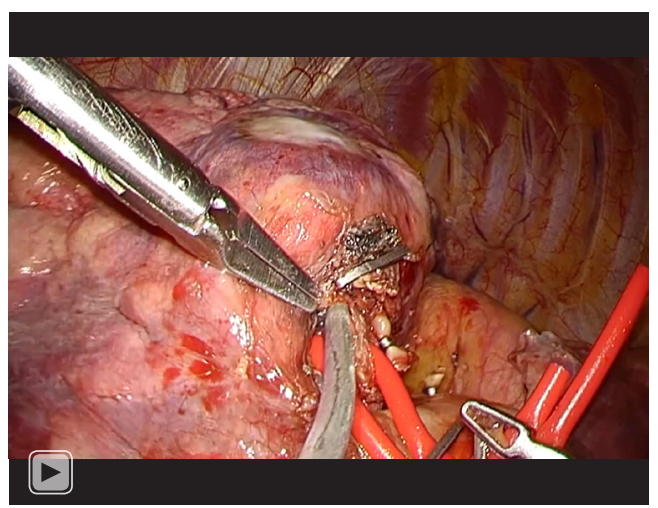

Video 4 Delineation of the intersegmental plane during a left S2 segmentectomy by selective bronchial insufflation.

applied (24). This is a cumbersome method because it requires intraoperative fibroscopy on a patient having a double-lumen tube and being placed in lateral decubitus.

Method 4: an alternate technique consists in stapling the bronchus and then puncturing its distal stump with a needle. The needle is connected to a catheter linked to a syringe and air is injected. This technique has given rise to gas embolisms which should make one very wary (25). In addition, the needle may actually be introduced not into a segmental bronchus, but into a subsegmental bronchus (Video 4).

Method 5: once the segmental vessels have been severed, the entire lung is ventilated with pure oxygen for 5 minutes. Then the segmental bronchus is stapled. The segment that is no longer vascularized retains oxygen since there is no more gas exchange and remains pink and aerated while the

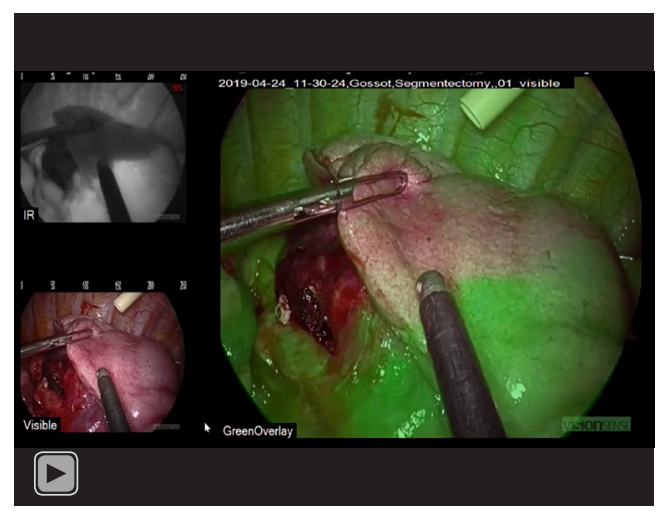

Video 5 Delineation of the intersegmental plane during a left S6 segmentectomy by infrared imaging.

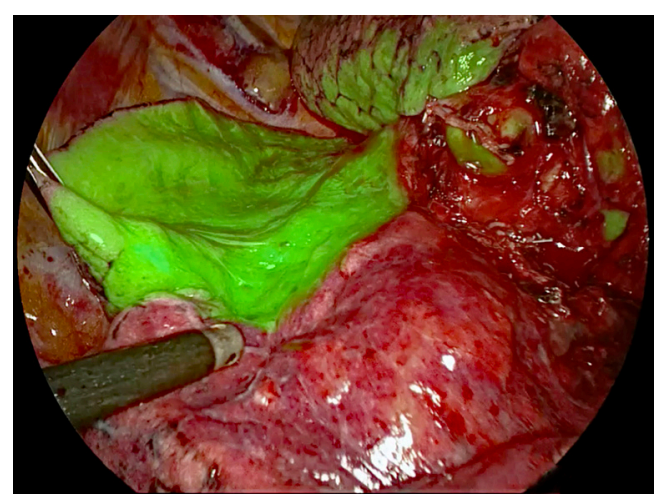

Figure 5 Example of delineation of the intersegmental plane lobe by infrared imaging after systemic injection of indocyanine green, during a right basilar segmentectomy.

remaining parenchyma turns purple (26).

Method 6: intrabronchial injection of a dye. The aim is to mark with a dye (indigo carmine or methylene blue) either the target segment or the adjacent segments. To do this, the sub-segmental bronchi of the segment are catheterized, either by fibroscopy or by ENB, injecting the dye and air to ease its diffusion. While this method effectively marks the segment(s), it delineates the margins very poorly and is therefore not very accurate.

Method 7: systemic indocyanine injection (Video 5). The technique is based on the fact that ICG, when it binds to plasma proteins and when stimulated by a laser, emits a near-infrared light. This light is detected by an infrared camera, which gives a green coloration to all vascularized tissues (Figure 5). Only the segment that has been devascularized keeps its natural color. Depending on 

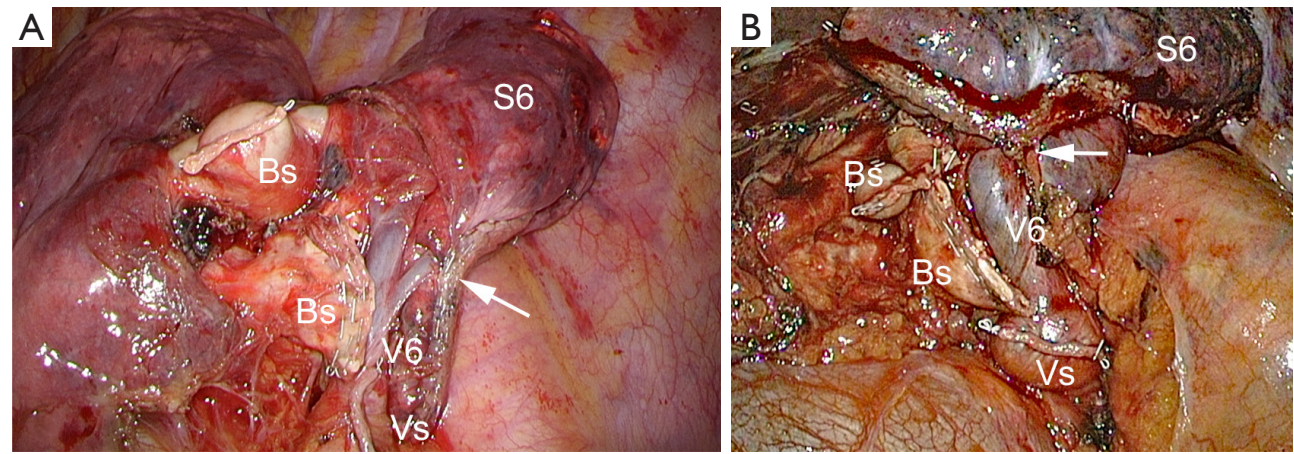

Figure $6 \mathrm{~V}^{6}$ vein at completion of a left basilar segmentectomy. (A) Preservation of the vein (arrow), (B) doubt on a squeeze of the $V^{6}$ vein by the staple line (arrow). Bs, stump of the basilar bronchus, As, stump of the basilar arterial trunk; Vs, stump of the basal veins.

the sensitivity of the system used, the green color appears more or less quickly, between 30 seconds and 2 minutes. It generally diffuses quite quickly, so that the marking of the intersegmental plane must be done rapidly, for example using cautery dots. The reliability of the method varies between $85 \%$ and $100 \%$ (27-30). The method can fail in patients with chronic obstructive bronchitis (COPD).

\section{Division of the intersegmental plane}

At the time of open surgery, surgeons favored opening the plane with electrocautery along the intersegmental vein, once the bronchus and arteries had been controlled. Hemostasis and aerostasis were controlled by HF-cautery, sutures and/or clips, possibly reinforced for some authors by application of biological glue or a fibrinogen patch $(31,32)$. The plane was left open.

This method has two advantages: the section is anatomical and the remaining parenchyma is functional. There are however shortcomings: the technique is difficult to apply via thoracoscopy, due to the lack of manual palpation. Oozing and/or true hemorrhage from the divided plane can be difficult to control thoracoscopically. If the section is perfectly anatomical, air leakage can be minimal. However, prolonged air leaks (33) are observed. Ohtsuka et al. showed that the use of cautery alone resulted in significantly more prolonged air leaks than when a combined method of electrocautery and stapling was used (34).

Separation by stapling is now the most commonly used technique during thoracoscopy. Once the line of demarcation is determined, a dedicated clamp is applied to the parenchyma (11). The clamp is closed to compress the parenchyma. This compression creates a mark on the squeezed parenchyma and then facilitates the application of the staple. The lung can be re-ventilated and the clamp possibly moved depending on the delineation line between ventilated and non-ventilated areas.

With few exceptions, the thickest staples are used. The availability of thick tissue staples $(5 \mathrm{~mm})$ and tri-staple technology has largely reduced staple line dehiscence that was sometimes observed with previous generations.

Advantages are the relative simplicity and speed of the procedure, the perfect hemostasis and satisfactory aerostasis, allowing rapid removal of chest tube and thus early discharge of the patient.

Disadvantages are the cost, the limited opening of the staplers, sometimes making it difficult to load thick parenchyma, the difficulty in maneuvering the stapler if the chest cavity is narrow, less precise and less anatomical division, risk of biting on the intersegmental vein if it has not been clearly identified (Figure 6).

Partial plication of the remaining segment(s), which would therefore be less functional, has been seen as a concern. This plication by compression of the parenchyma on the staple line is a reality but does not seem to have any clinical consequence, as demonstrated by our team (23). In an experimental study on sheep lung parenchyma, Asakura et al. showed that the volume of remaining parenchyma was indeed reduced if the entire section was done by stapling. But if the thin part of the fissure was sectioned with a scissor and the thick part stapled, there was no significant difference (31). Clinically, Miyasaka et al. showed no significant difference in respiratory function between these two methods (35).

Despite the drawbacks mentioned above, stapling is the most used method in recent series of thoracoscopic segmentectomies. But it is a delicate step of the operation, sometimes long and tedious, during which one should not 


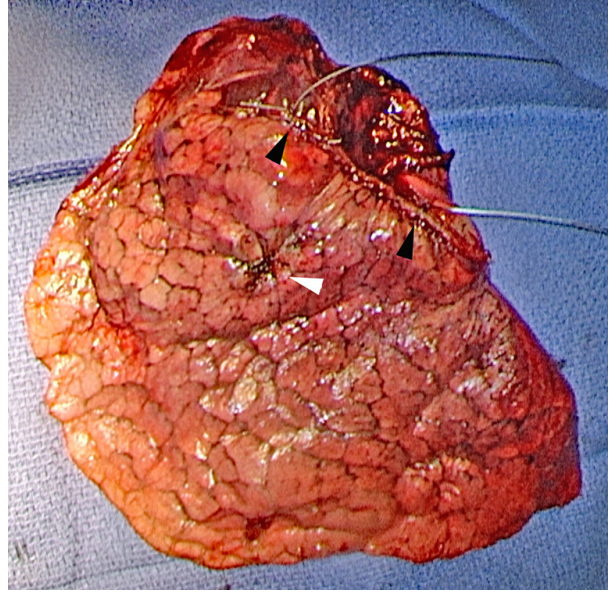

Figure 7 Example of intraoperative examination of the resection margins of a left $\mathrm{S}^{3}$ segmentectomy for a CT1a NSCLC. White arrow indicates nodule, black arrows indicate portion of the staple line to be examined by frozen section. NSCLC, non-small cell lung cancer.

hesitate to reposition the stapler several times to make sure it is in the appropriate direction. For basilar partial segmentectomies, using short reloads instead of $60 \mathrm{~mm}$ ones allows one to progress step by step and is safer.

\section{Intraoperative analysis of resection margins}

In oncological surgery, a segmentectomy is valid only if resection margins are sufficient. The rate of local recurrence is indeed correlated to the distance of these margins to the target tumor. Schuchert et al. have shown that segmentectomies have equivalent survival to lobectomies except when the margin/tumor diameter ratio is $<1$ with, in these cases, an increased risk of local recurrence (36). When this ratio is $>1$, the recurrence rate is significantly lower (25.0\% versus $6.2 \% ; \mathrm{P}=0.0014)$. In this study, the local recurrence rate was $7.7 \%$ and was observed in patients with a resection margin of less than $2 \mathrm{~cm}$. In our study of 284 TAS for cancer (19), resection margins were insufficient on intraoperative examination in 7 patients, leading to extend resection to another segment or even to the lobe. The study of resection margins by frozen section is essential because macroscopic examination is insufficient. Thus, the invasion of the resection margins was sometimes unexpected by the surgeon, who thought he was far away from the lesion (19). According to the recommendations (37), the resection margin should be at least equal to the largest diameter of the nodule and should be $2 \mathrm{~cm}$ for lesions whose largest diameter is $>2 \mathrm{~cm}$. Therefore, an intraoperative examination should be performed after removal of the staple line. Resection should be extended to lobectomy in case of doubtful margin. Since it is difficult to consider an examination of the entire resection margin, it is preferable to mark the limits of the area to be examined with 2 staystiches (19) (Figure 7).

Preoperative 3D modeling can help thanks to the virtual safety margin which shows if resection should be extended to an adjacent segment $(9,38)$ or if lobectomy should be considered.

\section{Intersegmental lymph node dissection}

The quality of thoracoscopic hilar, interlobar and intersegmental lymph node dissection to be done during thoracoscopic SLR is debated.

In our experience based on the previously cited study (19), the rate of correction from clinical TNM stage to higher pathological stage was $10.4 \%$. Concerning only the change of lymph node status from $\mathrm{cN} 0$ to $\mathrm{pN} 1$ or $\mathrm{pN} 2$, it is estimated in our series at $5.7 \%$. This rate is lower than that observed after lobectomy, which was $11.6 \%$ in the series by Boffa et al. (39), but is explained by the predominance of clinical stage IA. In a very large study of 11,531 patients, Boffa et al. showed that the rate of upstaging from N0 to $\mathrm{N} 2$ was not significantly different between thoracotomy and thoracoscopy but that there was a clear difference in favor of thoracotomy for the rate of upstaging from $\mathrm{N} 0$ to N1. This difference decreased with the experience of the operator. With experience, it is indeed possible to make a more extensive dissection of the bronchovascular pedicles, to sample the lymph nodes and thus to make an intraoperative examination at the slightest doubt if an intersegmental lymph node seems suspicious (19) (Video 6).

Studies have emphasized the importance of intersegmental lymph node dissection during thoracoscopic segmentectomies. Two studies have shown that in early-stage non-small cell lung cancer (NSCLC), lobectomies had better overall and recurrence-free survival than segmentectomies except when the latter were associated with lymph node dissection $(40,41)$. In the study of Xiao et al., the probability of finding positive isolated and remote LN (iLNs) was $40 \%$ when an adjacent node (aLN) was invaded (42) (Figure 8). The authors concluded that when an aLN was metastatic at frozen section, segmentectomy should not be recommended and resection should be extended to lobectomy, a rule now adopted by many teams $(15,19,42,43)$. 


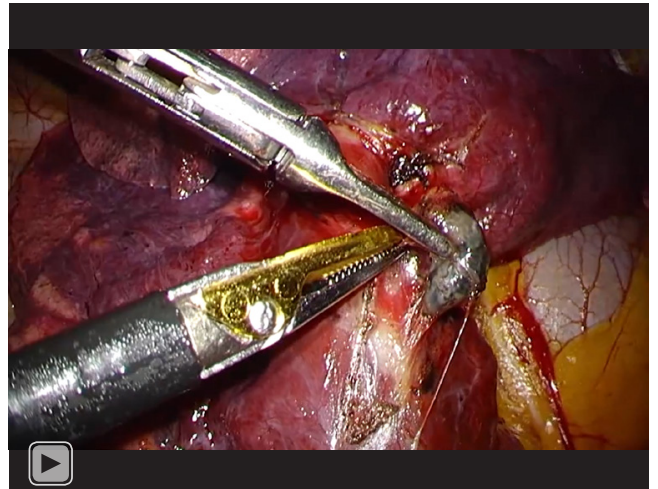

Video 6 Dissection and intraoperative examination of an intersegmental lymph node during a right S8 thoracoscopic segmentectomy.

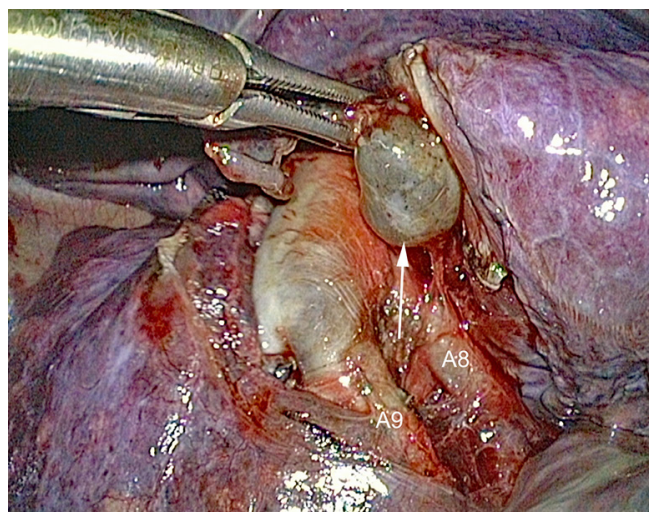

Figure 8 Example of an intersegmental lymph node to be examined by frozen section, during a right $\mathrm{S}^{8}$ segmentectomy. In this case: node (white arrow) station 12 is located between $\mathrm{A}^{8}$ and $\mathrm{A}^{9}$ arteries.

In summary, the performance of closed-chest SLR requires a rigorous technique based on an optimal comprehension and visualization of the anatomy. The preparation of the procedure is an essential step that comprises several aspects: (I) visualization of the target nodule in relation to the segment(s) to be resected with an analysis and planning of the safety margins; (II) modelization of the anatomy; (III) if necessary, labeling of the target. The procedure itself requires a fissure-based approach to avoid missing anatomical variations. The fissure must be widely open for an optimal vision of the vessels. Intraoperative analysis of the intersegmental lymph nodes and resection margins is essential to extend the resection to a lobectomy at the slightest doubt and to respect the criteria of oncological surgery.

\section{Acknowledgments}

Funding: None.

\section{Footnote}

Provenance and Peer Review: This article was commissioned by the Guest Editor (Michel Gonzalez) for the series "VATS Segmentectomy" published in Fournal of Visualized Surgery. The article has undergone external peer review.

Conflicts of Interest: All authors have completed the ICMJE uniform disclosure form (available at https://jovs. amegroups.com/article/view/10.21037/jovs-21-30/coif). The series "VATS Segmentectomy" was commissioned by the editorial office without any funding or sponsorship. DG received fees from Medtronic company for presentations in relation with this topic and royalties on instruments sales from Delacroix-Chevalier. ASG received consulting fees from Astra Zeneca and honoraria for presentations from Medtronic. The authors have no other conflicts of interest to declare.

Ethical Statement: The authors are accountable for all aspects of the work in ensuring that questions related to the accuracy or integrity of any part of the work are appropriately investigated and resolved. All procedures performed in this study were in accordance with the Helsinki Declaration (as revised in 2013). The manuscript is waived from patient informed consent according to the ethics committee or institutional review board.

Open Access Statement: This is an Open Access article distributed in accordance with the Creative Commons Attribution-NonCommercial-NoDerivs 4.0 International License (CC BY-NC-ND 4.0), which permits the noncommercial replication and distribution of the article with the strict proviso that no changes or edits are made and the original work is properly cited (including links to both the formal publication through the relevant DOI and the license). See: https://creativecommons.org/licenses/by-nc-nd/4.0/.

\section{References}

1. Cao C, Tian DH, Wang DR, et al. Sublobar resectionscurrent evidence and future challenges. J Thorac Dis 
2017;9:4853-5.

2. Cheng K, Zheng B, Zhang S, et al. Feasibility and learning curve of uniportal video-assisted thoracoscopic segmentectomy. J Thorac Dis 2016;8:S229-34.

3. Hamada A, Oizumi H, Kato H, et al. Learning curve for port-access thoracoscopic anatomic lung segmentectomy. J Thorac Cardiovasc Surg 2018;156:1995-2003.

4. Zhang Y, Liu S, Han Y, et al. Robotic Anatomical Segmentectomy: An Analysis of the Learning Curve. Ann Thorac Surg 2019;107:1515-22.

5. Le Gac C, Gondé H, Gillibert A, et al. Medico-economic impact of robot-assisted lung segmentectomy: what is the cost of the learning curve? Interact Cardiovasc Thorac Surg 2020;30:255-62.

6. Sato M, Murayama T, Nakajima J. Thoracoscopic staplerbased "bidirectional" segmentectomy for posterior basal segment (S10) and its variants. J Thorac Dis 2018;10:S1179-86.

7. Nomori H, Okada M. Illustrated anatomical Segmentectomy for Lung Cancer. Tokyo: Springer-Verlag, 2012.

8. Gossot D, Seguin-Givelet A. Anatomical variations and pitfalls to know during thoracoscopic segmentectomies. J Thorac Dis 2018;10:S1134-44.

9. Seguin-Givelet A, Grigoroiu M, Brian E, et al. Planning and marking for thoracoscopic anatomical segmentectomies. J Thorac Dis 2018;10:S1187-94.

10. Gossot D, Ramos R, Brian E, et al. A totally thoracoscopic approach for pulmonary anatomic segmentectomies. Interact Cardiovasc Thorac Surg 2011;12:529-32.

11. Gossot D. Atlas of endoscopic major pulmonary resections - 2nd edition: Springer-Verlag, 2017.

12. Yang Q, Xie B, Hu M, et al. Thoracoscopic anatomic pulmonary segmentectomy: a 3-dimensional guided imaging system for lung operations. Interact Cardiovasc Thorac Surg 2016;23:183-9.

13. Sekine Y, Itoh T, Toyoda T, et al. Precise Anatomical Sublobar Resection Using a 3D Medical Image Analyzer and Fluorescence-Guided Surgery With Transbronchial Instillation of Indocyanine Green. Semin Thorac Cardiovasc Surg 2019;31:595-602.

14. Oizumi H, Kanauchi N, Kato H, et al. Anatomic thoracoscopic pulmonary segmentectomy under 3-dimensional multidetector computed tomography simulation: a report of 52 consecutive cases. J Thorac Cardiovasc Surg 2011;141:678-82.

15. Handa Y, Tsutani Y, Mimae T, et al. Complex segmentectomy in the treatment of stage IA non-small-cell lung cancer. Eur J Cardiothorac Surg 2020;57:114-21.
16. Scott $W$, Howington J, Feigenberg S, et al. Treatment of non-small cell lung cancer stage I and stage II : ACCP evidence-based clinical practice guidelines (2nd edition). Chest. 2007;132:234-42.

17. Mariolo AV, Vieira T, Stern JB, et al. Electromagnetic navigation bronchoscopy localization of lung nodules for thoracoscopic resection. J Thorac Dis 2021;13:4371-7.

18. Mariolo AV, Seguin-Givelet A, Gossot D. Fatal Stroke After Reoperation for Lobar Torsion. Ann Thorac Surg 2020;110:e51-3.

19. Gossot D, Lutz JA, Grigoroiu M, et al. Unplanned Procedures During Thoracoscopic Segmentectomies. Ann Thorac Surg 2017;104:1710-7.

20. Eguchi T, Kato K, Shiina T, et al. Pulmonary torsion of the lingula following a segmentectomy of the left upper division. Gen Thorac Cardiovasc Surg 2008;56:505-8.

21. Brunswicker A, Farid S, Van Tornout F. Infarction of the lingula following left upper lobe trisegmentectomy. Asian Cardiovasc Thorac Ann 2016;24:107-9.

22. Gossot D, Mariolo A, Grigoroiu M, et al. Thoracoscopic complex basilar segmentectomies: an analysis of 63 procedures. J Thorac Dis 2021;13:4378-87.

23. Ojanguren A, Gossot D, Seguin-Givelet A. Division of the intersegmental plane during thoracoscopic segmentectomy: is stapling an issue? J Thorac Dis 2016;8:2158-64.

24. Okada M, Mimura T, Ikegaki J, et al. A novel video-assisted anatomic segmentectomy technique: selective segmental inflation via bronchofiberoptic jet followed by cautery cutting. J Thorac Cardiovasc Surg 2007;133:753-8.

25. Otsuka T, Nakamura Y, Harada A, et al. Extremely rare but potential complication of diffuse brain edema due to air embolism during lung segmentectomy with selected segmental inflation technique by syringe needle during video-assisted thoracoscopic surgery. J Thorac Cardiovasc Surg 2011;142:e151-2.

26. Iwata H, Shirahashi K, Mizuno Y, et al. Surgical technique of lung segmental resection with two intersegmental planes. Interact Cardiovasc Thorac Surg 2013;16:423-5.

27. Abdelsattar ZM, Blackmon SH. Using novel technology to augment complex video-assisted thoracoscopic single basilar segmentectomy. J Thorac Dis 2018;10:S1168-78.

28. Bédat B, Triponez F, Sadowski SM, et al. Impact of nearinfrared angiography on the quality of anatomical resection during video-assisted thoracic surgery segmentectomy. J Thorac Dis 2018;10:S1229-34.

29. Mehta M, Patel YS, Yasufuku K, et al. Near-infrared mapping with indocyanine green is associated with an increase in oncological margin length in minimally invasive 
segmentectomy. J Thorac Cardiovasc Surg 2019;157:2029-35.

30. Pischik VG, Kovalenko A. The role of indocyanine green fluorescence for intersegmental plane identification during video-assisted thoracoscopic surgery segmentectomies. J Thorac Dis 2018;10:S3704-11.

31. Asakura K, Izumi Y, Kohno M, et al. Effect of cutting technique at the intersegmental plane during segmentectomy on expansion of the preserved segment: comparison between staplers and scissors in ex vivo pig lung. Eur J Cardiothorac Surg 2011;40:e34-e38.

32. Yoshimoto K, Nomori H, Mori T, et al. Comparison of postoperative pulmonary function and air leakage between pleural closure vs. mesh-cover for intersegmental plane in segmentectomy. J Cardiothorac Surg 2011;6:61.

33. Palade E, Passlick B, Osei-Agyemang T, et al. Videoassisted vs open mediastinal lymphadenectomy for Stage I non-small-cell lung cancer: results of a prospective randomized trial. Eur J Cardiothorac Surg 2013;44:244-9.

34. Ohtsuka T, Goto T, Anraku M, et al. Dissection of lung parenchyma using electrocautery is a safe and acceptable method for anatomical sublobar resection. J Cardiothorac Surg 2012;7:42.

35. Miyasaka Y, Oh S, Takahashi N, et al. Postoperative complications and respiratory function following segmentectomy of the lung - comparison of the methods of making an inter-segmental plane. Interact Cardiovasc Thorac Surg 2011;12:426-9.

36. Schuchert MJ, Pettiford BL, Keeley S, et al. Anatomic segmentectomy in the treatment of stage I non-small cell lung cancer. Ann Thorac Surg 2007;84:926-32; discussion 932-3.

37. Howington J, Blum M, Chang A, et al. Treatment of

doi: $10.21037 /$ jovs-21-30

Cite this article as: Gossot D, Mariolo AV, Brian E, Boddaert G, Seguin-Givelet A. Full thoracoscopic segmentectomies for lung cancer: rational of a multiportal fissure-based approach. J Vis Surg 2022;8:23. stage I and II non-small cell lung cancer: Diagnosis and management of lung cancer, 3rd ed: American College of Chest Physicians evidence-based clinical practice guidelines. Chest 2013;143:278S-313S.

38. Iwano S. Planning video-assisted thoracic surgery segmentectomy using three dimensional computed tomography angiography and bronchography with a virtual safety margin. J Vis Surg 2017;3:82.

39. Boffa DJ, Kosinski AS, Paul S, et al. Lymph node evaluation by open or video-assisted approaches in 11,500 anatomic lung cancer resections. Ann Thorac Surg 2012;94:347-53; discussion 353 .

40. Huang Q, Wang R, Gu C, et al. Appropriate lymphadenectomy significantly reduced recurrence after segmentectomy for patients with non-small cell lung cancer. J Thorac Dis 2018;10:1919-26.

41. Wolf AS, Richards WG, Jaklitsch MT, et al. Lobectomy versus sublobar resection for small $(2 \mathrm{~cm}$ or less) non-small cell lung cancers. Ann Thorac Surg 2011;92:1819-23; discussion 1824-5.

42. Xiao F, Yu Q, Zhang Z, et al. Novel perspective to evaluate the safety of segmentectomy: clinical significance of lobar and segmental lymph node metastasis in cT1N0M0 lung adenocarcinoma. Eur J Cardiothorac Surg 2018;53:228-34.

43. Matsumura Y, Hishida T, Yoshida J, et al. Reasonable extent of lymph node dissection in intentional segmentectomy for small-sized peripheral non-smallcell lung cancer: from the clinicopathological findings of patients who underwent lobectomy with systematic lymph node dissection. J Thorac Oncol 2012;7:1691-7. 